\title{
Correction to: Metabolic profiling of pale green and purple kohlrabi (Brassica oleracea var. gongylodes)
}

\author{
Chang Ha Park ${ }^{1} \cdot$ Hyeon Ji Yeo ${ }^{1} \cdot$ Nam Su Kim ${ }^{1} \cdot$ \\ Ye Eun Park ${ }^{1}$ - Sun-Ju Kim² Mariadhas Valan Arasu $^{3}$. \\ Naif Abdullah Al-Dhabi ${ }^{3}$ Soo-Yun Park ${ }^{4} \cdot$ Jae Kwang Kim $^{5}$. \\ Sang Un Park ${ }^{1}$
}

Published online: 21 May 2018

(C) The Korean Society for Applied Biological Chemistry 2018

\section{Correction to: Appl Biol Chem (2017) 60(3):249-257 https://doi.org/10.1007/s13765-017-0274-z}

Unfortunately, in the online published article, the second author's given name was wrongly published. The correct given name should be "Hyeon Ji".
Similarly the fourth author's given name and family name was swapped. The given name should be "Ye Eun" and family name should be "Park".

The original article can be found online at https://doi.org/10.1007/ s13765-017-0274-z.

Chang Ha Park and Hyeon Ji Yeo have contributed equally to this work.

Jae Kwang Kim

kjkpj@inu.ac.kr

$\bowtie$ Sang Un Park

supark@cnu.ac.kr

1 Department of Crop Science, Chungnam National University, 99, Daehak-Ro, Yuseong-gu, Daejeon 34134, Republic of Korea

2 Department of Bio-Environmental Chemistry, Chungnam National University, 99, Daehak-Ro, Yuseong-gu, Daejeon 34134, Republic of Korea

3 Department of Botany and Microbiology, Addiriyah Chair for Environmental Studies, College of Science, King Saud University, P. O. Box 2455, Riyadh 11451, Saudi Arabia

4 National Institute of Agricultural Sciences, Rural Development Administration, Wanju-gun, Jeonbuk 55365, Republic of Korea

5 Division of Life Sciences and Convergence Research Center for Insect Vectors, Incheon National University, 119, Academy-ro, Yeonsu-gu, Incheon, Republic of Korea 